\title{
From the Grave to the Cradle: Evidence That Mortality Salience Engenders a Desire for Offspring
}

\author{
Arnaud Wisman \\ University of Kent
}

\author{
Jamie L. Goldenberg \\ University of South Florida
}

\begin{abstract}
On the basis of terror management theory, the authors hypothesized that reminders of mortality (mortality salience) should promote the desire for offspring to the extent that it does not conflict with other self-relevant worldviews that also serve to manage existential concerns. In 3 studies, men, but not women, desired more children after mortality salience compared with various control conditions. In support of the authors' hypothesis that women's desire for offspring was inhibited as a function of concerns about career success, Study 3 showed that career strivings moderated the effect of mortality salience on a desire for offspring for female participants only; furthermore, Study 4 revealed that when the compatibility of having children and a career was made salient, female participants responded to mortality salience with an increased number of desired children. Taken together, the findings suggest that a desire for offspring can function as a terror management defense mechanism.
\end{abstract}

Keywords: mortality salience, desire for offspring, gender, procreation, existential concerns

September 11th (2001) shook the foundations of liberty and democracy in the United States of America. Nevertheless, this dramatic episode in American history did not destroy the American spirit. On the contrary, the event made the American people conscious of the pride that they take in their country and its democratic history (Pyszczynski, Solomon, \& Greenberg, 2003). The streets of New York City were flooded with an atmosphere of patriotism, mourning, and togetherness shortly after the attack. In the wake of September 11th, another unusual observation was reported: The marriage rate increased, and hospitals all over the country expected a baby boom (CNN, May 2002). Experiencing a terrorist attack and a potential baby boom may appear paradoxical, but is there a link between experiencing such terrifying disasters and the desire to have offspring?

The observation of a link between disasters and a baby boom is in itself not novel (e.g., Cohan \& Cole, 2002). There are assumptions in the literature that such events may shape important life-course decisions by either functioning as a wake-up call (Martin, 1999) or by

Arnaud Wisman, Department of Social Psychology, University of Kent, Canterbury, United Kingdom; Jamie L. Goldenberg, Department of Psychology, University of South Florida.

This research was facilitated by Netherlands Organization for Scientific Research Grant 42521003. We are indebted to numerous academic colleagues and friends, in addition to those referred to in the article. We thank Jamie DeCoster, Katrin Finkenauer, Marcello Gallucci, Carmen Gonzalez, Gün Semin, and Ilan Shrira for their inspirational thoughts and careful feedback on an earlier draft of this article.

Correspondence concerning this article should be addressed to Arnaud Wisman, Department of Social Psychology, University of Kent, Canterbury, Kent CT2 7NP, United Kingdom. E-mail: a.wisman@kent.ac.uk increasing the need for close relationships (Cohan \& Cole, 2002; Mikulincer, Florian, \& Hirschberger, 2003). Aside from rational and relational reasons to desire children, a desire for offspring might be motivated by emotional and individual desires to leave something behind in this world. To the extent this motivation affects reproductive desires, having children may represent a way to deal with the threat of death. Nevertheless, the literature offers no conclusive theoretical framework to explain this often observed correlational connection between severe threats and an apparent striving for offspring.

In this article, a novel theoretical account is advanced for the causal relationship between life threatening events and the desire for offspring. According to terror management theory (TMT; Solomon, Greenberg, \& Pyszczynski, 1991), to cope with existential concerns, people adhere to worldviews that provide a sense of meaning and set the standards through which one can attain a sense of value (i.e., self-esteem). By living up to such standards, individuals obtain a sense of immortality by feeling that one is part of something more meaningful and longer lasting than one's own existence (Greenberg et al., 1990; Solomon et al., 1991). From this perspective, procreation can be regarded as a potential means to regulate concerns about mortality. After all, having children provides a sense of meaning and value (Baumeister, 1991) and can provide an avenue to immortality. Therefore, a relevant hypothesis that surprisingly has not yet been addressed is whether mortality concerns promote a desire for offspring.

However, having children may also pose costs that may interfere with defenses against mortality concerns outlined by TMT. In particular, women tend to have greater responsibilities in caring for offspring, and the burden of this responsibility can pose a direct threat to women's ability to derive meaning and value through the also culturally valued role of being a successful career woman. 
Thus, in this research we address the important question of whether mortality salience influences the desire for offspring differentially for men and women. To examine these issues, we report four experimental studies that investigate the key hypotheses of this theoretical framework.

\section{TMT}

The ends of life are marked by birth and death. The laws of nature are straightforward; after people are born there is no turning back. Although the future may seem unpredictable, the final episode of physical life is not; that is, in the end, the end is the end. As soon as people are cognitively capable, they start to ponder death and seek strategies to manage the concerns about mortality (Florian \& Mikulincer, 1998a). Terror arises from the juxtaposition of a biological creature programmed for survival with the ability to reflect on its vulnerabilities and mortality (Becker, 1973). Becker (1973) argued that this paradox of the human condition is at the core of human motivation. On the basis of the writings of existential thinkers like Kierkegaard, Rank, and Becker, TMT provides a systematic analysis of how one's fear of death (terror) is managed (Greenberg, Solomon, \& Pyszczynski, 1997; Pyszczynski, Greenberg, \& Solomon, 1999; Solomon et al., 1991).

TMT postulates that human beings use the same cognitive capabilities that render them aware of the problem of mortality in the first place to develop means of managing the problem. Specifically, the management of terror is posited to occur via a symbolic system of defense in which culturally constructed views of the world provide protection by offering a sense of meaning and, importantly, a promise of symbolic immortality to individuals who uphold cultural standards (Greenberg et al., 1997). That is, by living up to meaning-conferring cultural standards, people can feel as if they are part of something significant and lasting. People who subscribe to religious worldviews are even promised literal immortality, to the extent that they believe that living up to religious standards guarantees them entry into some kind of afterlife. Thus, reminders of mortality operate on an unconscious level to activate this psychological immune system and increase the need to adhere to meaningful conceptions of the world and to feel as if one is attaining one's culture's standards (i.e., self-esteem). Thus, in a sense, TMT elucidates why most people are not paralyzed with terror.

In support, research on TMT has demonstrated that reminders of one's mortality increase cognitive and behavioral efforts to maintain or defend the anxiety buffering structure by embracing one's cultural worldview and its standards of value. For instance, reminders of one's own death (i.e., mortality salience) have been found to lead to (a) increased preference for those who praise or share one's beliefs (Greenberg, et al., 1990; Greenberg, Simon, Pyszczynski, Solomon, \& Chatel, 1992), (b) harsher judgments against those who violate one's moral principles (e.g., Florian \& Mikulincer, 1997; Rosenblatt, Greenberg, Solomon, Pyszczynski, \& Lyon, 1989), (c) increased rejection and avoidance of out-group members (e.g., Greenberg et al., 1990; Ochsmann \& Mathay, 1996), and (d) increased identification with a successful ingroup and decreased identification with a unsuccessful ingroup (Arndt, Greenberg, Schimel, Pyszczynski, \& Solomon, 2002; Dechesne, Janssen, \& van Knippenberg, 2000). Furthermore, people try more fervently to measure up to personally relevant cultural standards when primed with mortality salience (e.g., Ben-Ari, Florian, \&
Mikulincer, 1999; Goldenberg, Arndt, Hart, \& Brown, in press); in fact, such attempts to boost one's self-esteem are often pursued even when to do so could pose a direct threat to one's life (e.g., driving fast; Ben-Ari et al., 1999). By and large, these studies have shown that cultural worldviews and self-esteem function as a psychological defense against existential concerns (for a broad review, see Greenberg et al., 1997); moreover, the nature of defense against mortality concerns are not direct remedies for the problem of death but rather are indirect solutions that operate on a psychological level.

More important, the described effects are found in response, not to conscious contemplations of mortality, but to recently activated concerns about mortality that are no longer consciously accessible. It is when mortality concerns are unconscious that they activate symbolic defenses pertinent to the individual's bases of meaning and value (e.g., Arndt, Greenberg, Pyszczynski, \& Solomon, 1997). Indeed, in most TMT research, symbolic defenses are assessed when an explicit contemplation of one's mortality is followed by an intervening delay (e.g., Greenberg, Pyszczynski, Solomon, Simon, \& Breus, 1994), or alternatively, unconscious mortality concerns can be activated via subliminal death primes (e.g., Arndt, Greenberg, Pyszczynski, \& Solomon, 1997). In short, TMT uniquely specifies the nature of psychological symbolic defenses against mortality concerns, showing specifically that people do not cope with unconscious mortality concerns with defenses that are rationally connected to the problem of death, but rather they do so through a symbolic solution that offers a sense of meaning and promise of symbolic immortality.

\section{Giving Birth to Immortality}

Although the previous research has illustrated that mortality salience exerts influence on a wide range of attitudes and behaviors, no studies have directly addressed the role of mortality reminders on people's desire for offspring. This is surprising because giving birth to a child seems to coincide with all the mechanisms that terror management theorists have suggested function to assuage mortality concerns. Having children can contribute to a sense of immortality, in both a literal and symbolic sense, and can help fortify a sense of meaning and self-worth. It seems reasonable then to conclude that having children may function as part of the psychological defense against existential concerns outlined by TMT.

At the most basic level, it makes sense that offspring can function as a defense against mortality concerns, for having children seems to be the most direct way of attaining, in a literal sense, immortality. As Becker (1973) suggested, "Nature conquers death not by creating eternal organisms but by making it possible for ephemeral ones to procreate" (p. 163). In a literal sense, offspring entail passing on about $50 \%$ of "the ephemeral ones" genes into a new generation. Indeed, a central tenet derived from evolutionary biology is that individual organisms behave as to maximize their fitness by propagating as many as possible of their own and related genes (Dawkins, 1982; Hamilton, 1964; Wilson, 1975). Supporting this idea of inclusive fitness, people are clearly more likely to invest in their own offspring. For example, Daly and Wilson (1988) reported that incidences of nonlethal child abuse and homicide correlate highly with nonbiological fatherhood, and Littlefield and Rushton (1986) revealed that the amount of bereavement is correlated with genetic relatedness. These findings demonstrate that biological hard-wired motives, such as inclusive fitness, may 
influence people's attitude toward offspring (see Belsky, Steinberg, \& Draper, 1991; Buss, \& Kenrick, 1998).

Although the premise that the desire for offspring is an evolved mechanism is intuitively appealing, evolutionary psychologists typically do not talk about evolution as fostering conscious desire to pass on one's genes, and specifically, it has been considered unlikely that humans evolved with a specific module for a desire for offspring (Veenhoven, 1975). The question of whether the desire for offspring is an evolved mechanism is complicated and is not the primary focus of this article (although we do address this possibility more comprehensively in the General Discussion section). However, this pending question certainly does not preclude the possibility that in human beings motivations informed by perspectives other than evolutionary psychology — such as the desire for literal immortality as a means to warding off fears of death (see Dechesne et al., 2003) — can promote a desire for offspring.

However, as terror management and other researchers (e.g., Sedikides \& Skowronski, 1997) have illustrated, in human beings the self is conceptualized in an abstract symbolic manner. As delineated above, individuals cope with concerns about mortality not simply by striving for literal immortality; however, in human beings immortality striving often takes a symbolic form. Indeed, empirical research has provided evidence for the hypothesis that immortality strivings can function to assuage mortality concerns (Dechesne et al., 2003; Greenberg et al., 1997; Norenzayan, Hansen, \& Atran, 2003; Ochsmann, 1984; Osarchuk \& Tatz, 1973). Confronted with existential concerns, people seek ways to achieve immortality (Norenzayan et al., 2003), and having children may be one of the most efficient ways to prolong a form of symbolic existence. Thus, apart from providing a direct form of literal immortality, having offspring can contribute to a sense of symbolic immortality (Lifton, 1979; see also Florian \& Mikulincer, 1998b; Greenberg et al., 1997). That is, children can represent for parents a means of leaving something behind in this world after their own literal demise. For example, one can simply hope to be remembered as a loving and caring parent or, more ambitiously, view one's children as inheritor of one's ideology or business. These kinds of immortality strivings are highly intertwined with cultural worldviews (Lifton, 1979). For instance, in one culture a parent may hope to be remembered as a brave warrior, whereas in another culture one may hope to be remembered as an understanding open-minded parent. Thus, people can strive for some means of symbolic self-continuation through their offspring within the context of a cultural-meaningful universe.

Although one's offspring can confer symbolic meaning to the parent in the hereafter, in the here and now, having children can provide a large degree of meaning and value to the life of the parent. Indeed, certainly in Western culture, people expect their children to supply an important source of meaning in life (for a broad overview, see Baumeister, 1991; Callan \& Hennesey, 1989a; Greil, 1997). People who suffer from infertility, for instance, often go through long periods of feelings of meaninglessness (Callan, 1987; Callan \& Hennessey, 1989b). By the same token, childless people are perceived by others to lack fulfillment (e.g., Baumeister, 1991). Moreover, traditional societies have relied on their offspring as a kind of retirement pension, providing some security (food, shelter, etc.) in the remains of their days (Zhan \& Montgomery, 2003). Closer to home, aged parents often expect filial responsibilities from their children (Hamon \& Blieszner, 1990).
Although children do not always meet the expectations of parents, research has revealed that loneliness was reduced by affection of their offspring (Long \& Martin, 2000). Moreover, having children might provide a sense of meaning in a more indirect way. Parents may attain a sense of meaning by basking in the glory of their successful children (e.g., Cialdini et al., 1976; Tesser, 1988). Some parents even seem to risk the well-being of their own children to help their children achieve at the highest level (from beauty queen to chess champion or whale hunter, depending on the culture). It is likely that parents motivate their children to pursue roles that are highly valued within the context of their cultural worldviews because to do so also reflects positively on their own self. In a sense, children can become a symbolic extension of the self (e.g., Sedikides \& Skowronski, 1997). In sum, it seems that having offspring can represent multiple powerful pathways to meaning and thus a sense of value within the context of an individual's worldview.

For all these reasons, it is not surprising in light of the TMT that people desire offspring and that they may be more likely to do so after being reminded of their mortality. First, having children entails a promise of literal and symbolic immortality; second, people expect that having offspring provides a powerful source of meaning and self-worth. In sum, there is substantial theoretical evidence suggesting that a desire for offspring functions as part of people's symbolic defense system against existential concerns. Thus, we see these different motivations for having offspring as complementary to one another, to the extent that they are all part of a cultural anxiety buffer and as such can play a role in the management of existential terror. Consequently, on the basis of the TMT, the prediction can be made that a reminder of mortality promotes a striving for procreation. Thus, although the ends of life are marked by birth and death, the recognition of death may be the cradle of new life.

\section{A Gender Engendering Perspective on a Desire for Offspring}

In the current series of studies, we demonstrate support for the hypothesis that the desire for offspring can function as a terror management defense by making specific predictions as to for whom and under what conditions mortality salience would be expected to influence this desire. In particular, we suggest that whereas men would be expected to increase their desired offspring after contemplating their death, women's reactions may be more complex. Of course, for women childbirth is complicated by the fact that women and men carry different "weights" with respect to having children. The physical consequences of maternity for female mammals (such as pain, bodily changes, and health risks) outweigh the costs for male mammals (Buss, 1996; Buss \& Kenrick, 1998; Trivers, 1985). However, although we believe that such differences between the genders certainly contribute to male's and female's attitudes and behaviors with regard to procreation, following other research on TMT, reminders of one's mortality should promote a need to manage mortality concerns through symbolic defenses. Thus, for women having offspring, although offering a pathway to meaning as well as immortality, also poses a threat to meaning and value derived via other culturally prescribed roles.

Although nowadays women participate in cultural practices (such as politics, arts, and science) that have been traditionally dominated by men (Mason \& Lu, 1988; Thornton, 1989; Wilkie, 
1993), when it comes to family roles, gender differences are still profuse (Cassidy \& Warren, 1996). For instance, in response to increased career opportunities for women, women more often than not have to juggle the responsibilities of their new role as a career woman and their more traditional responsibilities of wife and mother (Kiecolt, 2003; Spitze, 1988). In contrast, men more rarely combine having a career with a significant care-taking role in the family (Biernat \& Wortman, 1991). Indeed, research has shown that the double role of both worker and primary care provider causes overstrain among women (Wortman, Biernat, \& Lang, 1991). This may lead women to be more conflicted than men about their performance in home roles, especially among married couples with young children and relatively equal status careers (Biernat \& Wortman, 1991).

It seems reasonable, therefore, to speculate that women who emphasize the cultural value of a career anticipate a conflict when thinking about having children. If our position is valid, then this would be especially likely among women with high career strivings after a mortality salience induction. To be clear, we are not saying that women do not desire offspring as much or even more than men, or even that women's desire for offspring may not be enhanced by mortality salience in the same way it is for men. However, if another salient need contradicts the desire for offspring, then mortality salience may not lead to an increase in the desire for offspring among women. These predictions are in line with other research demonstrating that people's symbolic defenses against existential concerns are flexible in the face of multiple anxiety buffers (Dechesne et al., 2003; Wisman \& Koole, 2003). For instance, it has been found that participants who supported two sport teams in different sport disciplines (baseball and football) identified strongest with the most successful sport team after mortality salience (Dechesne, Greenberg, Arndt, \& Schimel, 2000). More to the extreme of flexible defenses, Wisman and Koole (2003) found that participants who were reminded of their own mortality expressed a relative preference to hide in a crowd of different-minded people over defending their own worldview in an isolated position. This kind of research is compatible with the multifaceted self-regulation concept and TMT, which suggests that defenses against mortality concerns are used in a rather flexible manner (Dechesne et al., 2003; Steele, 1988; Tesser, Crepaz, Beach, Cornell, \& Collins, 2000; Tesser, Martin, \& Cornell, 1996; Wisman \& Koole, 2003).

\section{The Current Research and Hypotheses}

By applying this dynamic model of defense to the question of how to predict both genders' desire for offspring after mortality salience, we generated the following hypotheses. Among women who foresee a successful career, such as students, a reminder of death might promote career strivings that at the same time impede a desire for offspring due to the aforementioned ambivalence of combining a career with having children (McKinney, 1987). Indeed, pilot data (see Study 4) revealed that the majority of the female participants viewed having children as a threat to career opportunity, and women perceived their careers as more threatened by having children than did men. Thus, self-relevant views (i.e., career strivings) potentially conflict with a desire for offspring and thus may result in a decreased desire for offspring after mortality salience. However, if the conflicting aspects of the self-relevant worldview are reduced (e.g., if a career is less relevant or children are perceived as compatible with one's career), then the desire to have offspring should offer a viable psychological defense against mortality concerns, and women are consequently expected to have a relatively stronger desire for offspring after mortality salience. In contrast, both children and a career are usually perfectly compatible for men (because the caregiving tasks that might impede career advancement are mostly done by women or are not realistically anticipated by men; Biernat \& Wortman, 1991); thus, men are expected to show an increased desire for offspring after a reminder of death regardless of career ambitions.

Thus, TMT allows us to make specific causal predictions as to for whom and under what conditions mortality salience would increase the desire for offspring, however, it is also important to acknowledge that there are other motivations that may be rooted in a need to manage terror that may be related to, but distinct from, a desire for offspring as a defense against mortality concerns. For example, Mikulincer et al. (2003) recently argued and provided evidence for the proposition that close relationships can function as a shield against mortality concerns. Drawing on this, it can be hypothesized that mortality salience may promote people's desire for offspring as a by-product of close-relationship strivings (Cohan \& Cole, 2002). Indeed people often consider having children as an act of love and a seal of a happy relationship (Ingraham, 1999). However, we suggest that people's desire for offspring is, at most, partially motivated by relationship strivings. For people sometimes desire having children without the desire, or permission, of their partner, and people can long for offspring without having any close relationship at all. Although we certainly believe that closerelationship strivings are attached to strivings for offspring, we suggest that close-relationship strivings are only part of the story and thus do not account for our findings.

Another related, but we believe distinct, motivation is the desire for sex. There is an obvious connection between sex and offspring-one that we assume does not need to be spelled out. However, as with close relationships, we suggest the desire for offspring, independent of sexual desire, can function as a buffer against existential concerns. Certainly people can attain offspring without sex, either through adoption or a growing repertoire of fertility treatments, such as artificial insemination. Furthermore, in a series of experiments, Goldenberg and colleagues (e.g., Goldenberg, Cox, Pyszczynski, Greenberg, \& Solomon, 2002; Goldenberg, Pyszczynski, McCoy, Greenberg, \& Solomon, 1999) showed that mortality concerns often lead individuals to express decreased rather than increased interest in the physical aspects of sex. Thus, as with close relationships, we suggest that any influence of mortality salience on the desire for offspring cannot be wholly attributed to a desire for sex.

Thus, in this series of studies we manipulate mortality concerns and examine the effect on desired offspring, taking measures to control for close relationship and sexual strivings. Moreover, we also offer precise predictions concerning gender differences in the desire for offspring that we suggest allows us to pit a terror management explanation above and beyond other factors that can also affect the desire for offspring. We hypothesized that mortality salience should promote the desire for offspring among men, but not women, because for women having offspring may conflict with other defenses against mortality concerns. The first two studies were set up to test our basic hypothesis that reminders of death 
would lead to an increased desire for offspring among male participants but not among female participants. In a third study, we tested whether career ambition would conflict with women's, but not men's, desire for offspring as a function of mortality salience. Finally, in Study 4, we directly manipulated female participants' views with respect to the advisability of having children in conjunction with a successful career and tested whether undoing the source of conflict for women would allow for an increase in the desire for offspring.

\section{Study 1}

The first study was designed to examine the desire for offspring as a function of mortality salience and gender. To this end, we assessed the number of children desired after a traditional mortality salience prime. Because we were predicting differential effects for men and women, we measured the accessibility of deathrelated thoughts subsequent to the mortality salience induction to show that differential findings could not be attributed to a greater impact of the mortality salience prime among one gender. In particular, we hypothesized that men would respond to mortality salience with an increase in their desired number of offspring; however, women, because of a conflict between maternal responsibilities and career ambitions, would not respond with parallel increases in their desires for offspring.

In addition, we also assessed participants' current relationship status to ascertain whether any increase in desire for offspring could be attributed to a desire to be more intimate in one's close relationships (Mikulincer et al., 2003). If the desire for procreation is merely associated with a desire for closeness, then we would expect people who are involved in a serious relationship to be more likely to increase their desire for offspring to cope with existential concerns.

\section{Method}

\section{Participants and Design}

A total of 76 undergraduate students from the Free University of Amsterdam, the Netherlands ( 36 woman and 40 men, average age $=21$ years) were randomly assigned to either the mortality salience or control condition. Participants received around $\$ 2$ for their participation.

\section{Procedure and Materials}

On arrival in the laboratory, participants were welcomed and seated in separate cubicles, each containing a computer. All instructions and materials were administered via computer in Dutch. The study was described as consisting of a number of separate unrelated parts.

Mortality salience. The first part was described as research on personality and consisted of a few filler questionnaires followed by the mortality salience manipulation. Mortality salience was manipulated with the same two open-ended questions about death or a control topic that has been used in numerous TMT experiment (e.g., Rosenblatt et al., 1989). Specifically, participants were asked the following: (a) Describe the emotions you feel while you are thinking about your own death, and (b) Describe what you think will happen to you when you physically die. Control participants were asked two parallel questions about watching TV.

Self-reported affect. The manipulation was followed by the 20-item Positive and Negative Affect Scales (PANAS; Watson, Clark, \& Tellegen, 1988), which measure affect. The items were presented in random order and scored on a 5-point scale ranging from 1 (not at all) to 5 (very much).
The PANAS also served to provide a delay and distraction task after the manipulation, because previous TMT research has revealed the effects of mortality salience are specific to conditions in which individuals are no longer consciously attending to such thoughts (e.g., Greenberg et al., 1994).

Death accessibility. The PANAS was followed with a short translated version of the measure often implemented to gauge the accessibility of death-related thought (Arndt, Greenberg, Solomon, Pyszczynski, \& Simon, 1997). The scale consisted of 14 word fragments that were presented in random order. Four word fragments could be either completed with a death-related word or a death-unrelated word. For instance, the word fragment "DEA" could be completed as either "DEAL" or "DEAD." The remaining 10 word-fragments could be completed with only a deathunrelated word.

Desire for offspring. We assessed the number of desired offspring with two questions. Participants were asked the following: "How many children would you like to have in your fantasy?" and "How many children would you like to have in reality?" These two items were scored on a 6-point scale ranging from 0 (no children at all) to 6 (six children). We found that responses to these items were highly reliable and thus a single desire for offspring composite was created by averaging the two items (Cronbach's $\alpha=.89$ ). It was stressed that there were no good or bad responses and that participants should answer the questions in a quick and spontaneous manner.

Relationship status. Among some demographic items, participants' relationship status was assessed. Relationship status was assessed by one dichotomous yes-no item: "Are you currently involved in a romantic relationship?"

As a manipulation check, participants were asked about the purpose of the experiment (to which all participants were naive). Participants were subsequently debriefed and dismissed.

\section{Results}

\section{Self-Reported Affect}

A 2 (mortality salience: death vs. control) $\times 2$ (gender: men vs. women) between-subjects analysis of variance (ANOVA) was conducted on the two subscales of the PANAS. The analyses did not reveal any significant effects on either the positive or negative affect subscales (both $p s>.15$ ). This result is consistent with most other TMT research (e.g., Pyszczynski et al., 2003), finding that the mortality salience manipulation has no effect on self-reported mood.

\section{Death Accessibility}

The scores on the death accessibility scale were subjected to a 2 (mortality salience: death vs. control) $\times 2$ (gender: men vs. women) between-subjects ANOVA. This analysis yielded a significant main effect, showing that participants in the mortality salience condition completed more word fragments into deathrelated words relative to the control condition, $F(1,72)=4.66$, $p<.05$. Thus, the manipulation of mortality salience did have the desired effect of making mortality concerns more salient. More important, no main or interaction effects for gender were found ( $p s>.40)$, and thus, any discrepancy in the effects for men and women in response to mortality salience cannot be attributed to differential effectiveness of the manipulation.

\section{Number of Desired Children}

Desire for offspring was also subject to a 2 (mortality salience: death vs. control) $\times 2$ (gender: men vs. women) between-subjects ANOVA. The result yielded only the predicted Mortality Sa- 
lience $\times$ Gender interaction, $F(1,72)=6.11, p<.02$. As shown in Table 1, male participants displayed a wish for more children under mortality salience compared with control salience, $F(1$, 74) $=7.94, p=.006$. In contrast, no difference in desired offspring was found for female participants under mortality salience compared with the control condition $(p>.40)$.

\section{Relationship Status}

All analyses were repeated with relationship as a factor. No significant results were found for relationship ( $p$ s $>.30$ ), and including relationship status in the analysis did not affect the significant findings.

\section{Discussion}

The findings of Study 1 support our prediction that mortality salience would increase procreation strivings for men but not women. Male participants in the mortality salience condition displayed a wish for more children compared with the neutral condition. Female participants, however, were not affected by mortality salience and even showed a nonsignificant trend in the direction of desiring less offspring under mortality salience.

More important, it is not likely that these gender differences can be accounted for by differential effectiveness of the mortality salience manipulation for men and women because this manipulation has been used well over 100 times with no gender differences (see, e.g., Greenberg et al., 1997). Furthermore, our death accessibility manipulation check revealed that although there was a main effect of the mortality salience manipulation, there was no main or interaction effects involving gender. In addition, it is also notable that participants' relationship status did not alter any of the aforementioned findings. Of course, not being in a relationship does not preclude the possibility that one might desire offspring as a proxy for closeness to another; however, the failure to find any effect of relationship status in conjunction with the finding that mortality salience only increased procreation striving among men renders the alternative explanation that procreation striving can be accounted for by relationship striving extremely unlikely.

One alternative explanation left unexplored is whether the findings are specific to mortality concerns or whether such effects occur after contemplating any negative topic. Although we cannot

Table 1

Procreation Striving as Indicated by the Number of Desired Children as a Function of a Mortality Salience $\times$ Gender Interaction (Study 1)

\begin{tabular}{ccc}
\hline & \multicolumn{2}{c}{ Gender } \\
\cline { 2 - 3 } Mortality salience & Women & Men \\
\hline Control & & \\
$M$ & 2.53 & 2.00 \\
$S D$ & 0.81 & 0.87 \\
$n$ & 18 & 20 \\
Death & & \\
$M$ & 2.30 & 2.78 \\
$S D$ & 1.00 & 0.82 \\
$n$ & 18 & 20 \\
\hline
\end{tabular}

think of a rationale for why negative thoughts would lead men, and not women, to desire more offspring, we felt that it was critical to replicate these findings when mortality concerns were contrasted to an unpleasant control topic.

Study 2

Study 2 was therefore designed with two primary goals in mind. First, we sought to replicate the findings of Study 1 when mortality salience was contrasted with an aversive rather than a neutral topic. Second, although following the precedent of other terror management research, we viewed an increase in desired number of offspring in response to mortality salience to indicate that the desire for offspring was serving a terror management function, we wanted to test this assumption further by examining whether increased interest in offspring would in turn reduce further defensiveness against mortality concerns. If a desire for offspring is indeed part of the psychological anxiety buffer, then the activation of desires for offspring should provide protection against mortality salience and, as such, reduce responses on other subsequent measures that aim to tap defensiveness (see McGregor et al., 1998). Thus, we followed the desire of offspring measure with a worldview defense paradigm modeled after previous terror management research.

\section{Method}

\section{Participants and Design}

A total of 76 undergraduate students from the Free University of Amsterdam ( 38 woman and 38 men, average age $=21$ years) were randomly assigned to either the mortality salience or nondeath-related aversive control condition. Participants received around $\$ 2$ for their participation.

\section{Procedure and Materials}

As in Study 1, participants were welcomed and seated in separate cubicles, each containing a computer on which the instructions and all materials were administered.

Mortality salience. To compare mortality salience with another aversive topic, we asked participants in our control condition to think about a visit to the dentist. Specifically, participants were asked the following: (a) Describe the emotions you feel while you are thinking about (your own death/a visit to the dentist), and (b) Describe what you think will happen to you when you (physically die/visit the dentist).

Self-reported affect. Immediately following the mortality salience treatment, participants rated their current feelings on the PANAS.

Desire for offspring. As in Study 1, participants got the instruction to give fast responses in a spontaneous manner, followed by the two same questions about how many children participants desired. As in Study 1, these two items were averaged to form a composite measure (Cronbach's $\alpha=.90)$.

Worldview defense. In most terror management research (e.g., Greenberg et al., 1990; Rosenblatt et al., 1989), worldview defense has been assessed by participants' judgment of a pro-United States essay versus an anti-United States essay. However, the Netherlands is known for its tolerant worldviews toward people with different opinions, and moreover, tolerance has been a central tenet within Dutch society (Schama, 1997). Because prior research has shown that mortality salience can promote even more tolerance toward worldview threatening others among those who embraced tolerant worldviews (Greenberg et al., 1992), the anti-Dutch essay was deemed as not particularly suitable for tapping worldview 
defense in the Netherlands; consequently, only a pro-Dutch essay was used as a dependent measure of worldview defense (Wisman \& Koole, 2003; for other research revealing worldview defense effects only on a worldview supportive essay, see Hart, Shaver, \& Goldenberg, in press).

Thus, in the third part of the study, participants were asked to answer some questions regarding a short essay. This essay (Wisman \& Koole, 2003) was closely modeled after the pro-United States essay that has been used in previous terror management experiments (e.g., Greenberg et al., 1992). Specifically, this essay was supposedly written by a foreign student staying in the Netherlands and the essay delivered praise to Dutch culture. The pro-Dutch essay read as follows:

The first thing that strikes you right away is the total freedom that people have in this country. There are good opportunities for everyone, and the education system is excellent. You can achieve whatever you want and there is a unique system that protects people with lesser chances. I have to say that I admire Dutch people because of their hospitality and their tolerance. Of course there are some weak points in the Netherlands as well, but in general I think that you should be proud of the fact that so many people from different cultures can live here in harmony. Dutch people should be proud that people in the Netherlands live in a democratic and tolerant country.

The essay was followed by a questionnaire that asked participants to provide evaluations of the author and the essay. Five of these questions were based on the Interpersonal Judgment Scale (Byrne, 1971), and the two remaining questions were concerned with participants global evaluations of the essay (see Greenberg et al., 1990). Representative items based on the Interpersonal Judgment Scale were "Would you like to meet this person?" and "To what extent do you think this person uses good arguments?" The global evaluation items were "To what extent does this essay appeal to you?" and "Does this essay affect you in a positive or negative manner?" All questions were scored on 9-point scales ranging from 1 (not at all) to 9 (very much) or from 1 (very negative) to 9 (very positive).

After participants had evaluated the pro-Dutch essay, demographic information was assessed, and participants were probed for suspicion (all were naive), debriefed, and dismissed.

\section{Results}

\section{Self-Reported Affect}

A 2 (mortality salience: death vs. control) $\times 2$ (gender: men vs. women) between-subjects ANOVA was conducted on the two subscales of the PANAS. These analyses revealed a main effect for mortality salience on negative mood, $F(1,72)=4.85, p<.05$. Participants in the mortality salience condition reported more negative feelings than participants in the dental pain condition $(M=15.71, S D=5.71$ vs. $M=13.18, S D=4.09)$. This result is inconsistent with most terror management findings in which the mortality salience treatment, contrary to intuition, does not affect self-reported mood. There was, however, no interaction between mortality salience and gender $(p=.70)$, and thus, it is not likely that negative affect mediates the interaction effects reported below (Baron \& Kenny, 1986; MacKinnon, Lockwood, Hoffman, West, \& Sheets, 2002). However, in light of this finding, the analyses below were repeated with the inclusion of negative affect as a covariate; all significant effects remained the same and thus are presented only without the covariate. Analyses with the positive affect subscale of the PANAS did not approach significance ( $p$ s > $.30)$.

\section{Number of Desired Children}

The desire for offspring composite was subjected to a 2 (mortality salience: death vs. control) $\times 2$ (gender: men vs. women) between-subjects ANOVA. The analyses revealed a mortality Salience $\times$ Gender interaction, $F(1,72)=4.06, p<.05$. As shown in Table 2, male participants revealed a strong trend toward desiring more children under the mortality salience compared with the dental pain control condition, $F(1,74)=3.66, p=.06$. In contrast, female participants revealed a nonsignificant trend in the direction of desiring fewer children when mortality was salient, $F(1,74)=0.88, p>.30$. Thus, Study 2 provides converging support for the findings of Study 1, showing that mortality salience led to a somewhat greater desire for procreation among male participants and not among female participants.

\section{Worldview Defense}

An evaluation of the worldview supportive essay was created by aggregating the items that assessed reactions to the pro-Dutch essay. Six of the seven items were found to load on a single factor (loadings $>.60$ ). These items (excluding "This person seems to be intelligent") were averaged into a single pro-Dutch composite (Cronbach's $\alpha>$.80). Then, the pro-Dutch composite was subjected to a 2 (mortality salience: death vs. control) $\times 2$ (gender: women vs. men) between-subjects ANOVA. This analyses yielded a Gender $\times$ Mortality Salience interaction, $F(1,72)=4.39, p<$ .05. As shown in Table 3, female participants had a stronger preference for the pro-Dutch essay in the mortality salience condition compared with the control salience condition, $F(1,36)=$ $4.45, p<.05$. In contrast, male participants' preference for the pro-Dutch essay was not affected by the mortality salience manipulation $(p s>.50)$. That is, worldview defensive reactions were only found among female participants.

\section{Discussion}

The results of Study 2 provide evidence of a causal effect of a death reminder on the desire for offspring. As expected, relative to dental pain salience, mortality salience led to an increased number of desired children among male participants. In contrast, female participants did not display an increase in procreation strivings after mortality salience. Thus, consistent with the findings of Study

Table 2

Procreation Strivings as Indicated by the Number of Desired Children as a Function of a Mortality Salience $\times$ Gender Interaction (Study 2)

\begin{tabular}{ccc}
\hline & \multicolumn{2}{c}{ Gender } \\
\cline { 2 - 3 } Mortality salience & Women & Men \\
\hline Control & & \\
$M$ & 2.74 & 2.13 \\
$S D$ & 1.17 & 1.03 \\
$n$ & 19 & 19 \\
Death & & \\
$M$ & 2.37 & 2.87 \\
$S D$ & 1.23 & 1.33 \\
$n$ & 19 & 19 \\
\hline
\end{tabular}


Table 3

Pro-Netherlands Bias as a Function of a Mortality Salience $\times$ Gender Interaction (Study 2)

\begin{tabular}{ccc}
\hline & \multicolumn{2}{c}{ Gender } \\
\cline { 2 - 3 } Mortality salience & Women & Men \\
\hline Control & & \\
$M$ & 5.57 & 6.15 \\
$S D$ & 1.65 & 0.93 \\
$n$ & 19 & 19 \\
Death & & \\
$M$ & 6.44 & 5.97 \\
$S D$ & 0.69 & 0.79 \\
$n$ & 19 & 19 \\
\hline
\end{tabular}

1, increased desire for offspring appeared to serve a terror management response only for men. Converging evidence that these procreation strivings functioned as an anxiety buffer against mortality salience was provided by the findings that although female participants exhibited worldview defense after mortality salience, male participants did not. These findings are particularly powerful because (a) the same measurement of worldview defense has been used previously with no specific gender effects regarding worldview defense after mortality salience (Wisman \& Koole, 2003), (b) numerous experiments have shown that both women and men can use patriotic worldviews to cope death anxiety (see Greenberg et al., 1997), and (c) other studies have shown that male participants are even more prone to think about patriotic topics after mortality salience than women (Arndt, Greenberg, \& Cook, 2002). Thus, the findings - in response to mortality salience, men increased their desired number offspring but did not respond with increased worldview defense when it was subsequently measured and women showed no increase in desired offspring but did respond with increased worldview defense-provide particularly compelling evidence that for men, the desire for offspring can function as a buffer against existential concerns. The findings also provide evidence, consistent with Study 1, that women are not unaffected by mortality salience but rather are merely not defending with a desire for offspring, as are their male counterparts.

Thus the findings of Studies 1 and 2 provide evidence that the desire for offspring is a more viable worldview defense for men than women. However, these studies do not provide any explanation as to why this would be the case. The remaining two experiments were therefore designed to both replicate the current findings and provide direct evidence for our hypothesis that the conflict between maternal responsibilities and career ambition in women makes the desire for offspring a less viable means of responding to mortality concerns for women than men.

\section{Study 3}

Study 3 was designed to directly test the hypothesis that career ambition would conflict with women's, but not men's, desire for offspring as a function of mortality salience. Therefore, in this study career striving was assessed, and we tested whether it moderated the effects of mortality salience on the desire for offspring. We hypothesized that if children represent a conflict to women's but not men's careers, then career striving should moderate the effect of mortality salience for women but not for men. In addition, this study included an item that assessed level of sexual desire to confirm that the effects of Mortality Salience $\times$ Gender on the desire for offspring are attributable to a desire for offspring per se and not to differences in the desire for sex.

\section{Method}

\section{Participants and Design}

A total of 127 undergraduate students from the Free University of Amsterdam (73 woman and 54 men, average age $=21$ years) were randomly assigned to either the mortality salience or control condition. Participants received around $\$ 2$ for their participation.

\section{Procedure and Materials}

On arrival in the laboratory, participants were welcomed and seated in separate cubicles, each containing a computer on which all instructions and materials were administered.

Career strivings. The first part was described as research into personality and consisted of a few filler questionnaires and four items that were designed to measure participants' career strivings. Participants were asked to indicate to what extent they agreed with the following statements: (a) "I would never give up my career for my family," (b) "If I had to choose between a career and having children, I would choose having children," (c) "My highest priority is to concentrate on my studies to prepare for a career," and (d) "Having a career is relatively unimportant for me." Participants responded on a 9-point scale ranging from 1 (totally disagree) to 9 (totally agree). The items of the career striving scale loaded sufficiently on one factor (loadings $>.60$ ), and accordingly, the four items were appropriately scored and averaged into a single career strivings index (Cronbach's $\alpha=.67$ ).

Mortality salience. Participants were asked to respond to the same open-ended questions about death or a dental visit used in Study 2.

Self-reported affect. Again, the mortality salience manipulation was followed by the PANAS.

Desire for offspring. Again, participants got the instruction to give fast responses in a spontaneous manner, followed by the two same questions about how many children the participants desired (Cronbach's $\alpha=.89$ ).

Relationship status and sexual desire. Finally, participants filled out a form containing demographic items, including relationship status and an additional question that asked participants to indicate the extent to which they agreed with the following statement: "I have a salient desire for sex." Participants responded on a 9-point scale ranging from 1 (totally disagree) to 9 (totally agree).

As a manipulation check, participants were asked about the purpose of the experiment. Participants were then debriefed and dismissed.

\section{Results}

\section{Manipulation Check}

Three participants guessed the purpose of the experiment and, therefore, were excluded from the analyses.

\section{Self-Reported Affect}

A 2 (mortality salience: death vs. control) $\times 2$ (gender: men vs. women) between-subjects ANOVA was conducted on the two subscales of the PANAS. These analyses did not reveal any significant effects on the subscales of the PANAS $(p s>.20)$. The data below were therefore not analyzed with mood as a covariate. 


\section{Number of Desired Children}

The desire for offspring composite was subjected to a 2 (mortality salience: death vs. control) $\times 2$ (gender: men vs. women) between-subjects ANOVA. Once again, the result yielded a Mortality Salience $\times$ Gender interaction, $F(1,123)=13.23, p<.001$. As shown in Table 4, male participants displayed a wish for more children when mortality was salient compared with the dental visit control condition, $F(1,125)=11.39, p=.001$. In contrast, no effect was found for female participants as a function of mortality salience $(p=.12)$. Thus, Study 3 corroborated the findings of Studies 1 and 2, showing that mortality salience increased a desire for offspring among male participants and not among female participants.

\section{Relationship}

The above analyses were repeated with participant involvement in a stable romantic relationship as a factor. No significant results were found for relationship status ( $p s>.20)$, and including relationship status as a factor in the analysis did not affect the significant pattern of results.

\section{Desire for Sexuality}

We also tested whether the Mortality Salience $\times$ Gender interaction could be attributed to an increase in sexual desire. First, regression analysis in which sexual desire was treated as an outcome variable revealed a main effect of mortality salience on the desire for sex, $b=.220, S E=.298, t(125)=2.53, p=.018$, showing that mortality salience led to a reduction in sexual desire. Next, a three-step mediational analysis (Baron \& Kenny, 1986) was conducted, aimed at testing whether a desire for sexuality mediated the Mortality Salience $\times$ Gender interaction on a desire for offspring. We first regressed desire for offspring onto sexual desire scores, and this analysis did reveal a relationship between sexual desire and the desire for offspring, $b=-.361, S E=.052$, $t(125)=-4.32, p<.001$ (in the direction of more sexual desire being associated with a lesser appetite for having children). Second, we tested for the original Gender $\times$ Mortality Salience interaction on a desire for offspring using regression, first entering each main effect followed by the product term. The original interaction (not surprisingly) was significant, $b=-.293, S E=$

Table 4

Procreation Strivings as Indicated by the Number of Desired Children as a Function of a Mortality Salience $\times$ Gender Interaction (Study 3)

\begin{tabular}{ccc}
\hline & \multicolumn{2}{c}{ Gender } \\
\cline { 2 - 3 } Mortality salience & Women & Men \\
\hline Control & & \\
$M$ & 2.42 & 1.91 \\
$S D$ & 0.84 & 0.68 \\
$n$ & 37 & 27 \\
Death & & \\
$M$ & 2.03 & 2.85 \\
$S D$ & 1.19 & 1.13 \\
$n$ & 36 & 27 \\
\hline
\end{tabular}

$.091, t(123)=3.43, p<.001$. Finally, when we added participants' desire for sexuality scores to the regression analysis with the Mortality Salience $\times$ Gender interaction, the Gender $\times$ Mortality Salience interaction remained significant, $b=.245, S E=.087$, $t(119)=3.00, p<.005$. This pattern is not consistent with mediation (Baron \& Kenny, 1986; MacKinnon et al., 2002). Thus, these analyses suggest that the found Gender $\times$ Mortality Salience interaction on a desire for offspring was not mediated by participants' desire for sexuality.

\section{Career Strivings}

Lastly, to determine whether career strivings interacted with reminders of mortality to influence male and female participants' desire for offspring, we conducted multiple regression analysis with mortality salience, gender, and career striving in the analysis. Mortality salience, gender, and career striving scores were entered in the first step of the regression analysis, followed by the product terms for the two-way interactions and the three-way interaction term in the last step. The results revealed a main effect of career strivings, $b=-.250, S E=$ $.015, t(119)=-3.12, p<.005$, with participants with high career strivings desiring less children than those who had relatively lower career strivings, as well as the original Mortality Salience $\times$ Gender interaction, $b=.338, S E=.086, t(119)=$ $4.21, p<.0005$. These effects, however, were qualified by the predicted three-way interaction, $b=.162, S E=.015, t(119)=$ 2.03, $p<.05$. To explore the nature of this interaction, we assessed a desire for offspring among male and female participants separately as a function of mortality salience and career strivings at one standard deviation above and below the mean $(M=20.03, S D=5.83$; Cohen \& Cohen, 1983).

For men, results of multiple regression analysis only showed a main effect in which mortality salience increased men's desire for offspring, $b=-.441, S E=.141, t(50)=-3.46, p=.001$. Note, the null effect of career strivings as a moderator of the desire for offspring ( $p=.40$ ) was not caused by a lack of variability on the career striving index among male participants. Indeed, a Levene's test for equality of variances revealed that the two genders did not have a significantly different variance on the career striving index, $F(1,125)=0.13, p>.70$.

For women, the multiple regression analyses revealed a main effect of mortality salience, with female participants desiring relatively less children after mortality salience compared with the control condition, $b=.226, S E=.104, t(69)=2.24, p=.03$, and a main effect for career strivings, $b=-.463, S E=.019, t(69)=$ $-4.57, p<.0005$, in which female participants with high career strivings desired less children than those who had relatively lower career strivings. These main effects, however, were qualified by the predicted Mortality Salience $\times$ Career Strivings interaction for women, $b=.208, S E=.019, t(69)=2.06, p=.044$. As can be seen in Figure 1, the interaction shows that the desire for less children in response to mortality salience compared with the control condition was specific to women who were high in career striving, $b=.477, S E=.144, t(69)=3.21, p=.002$. There was no effect for female participants with low career strivings ( $p=$ .97). 


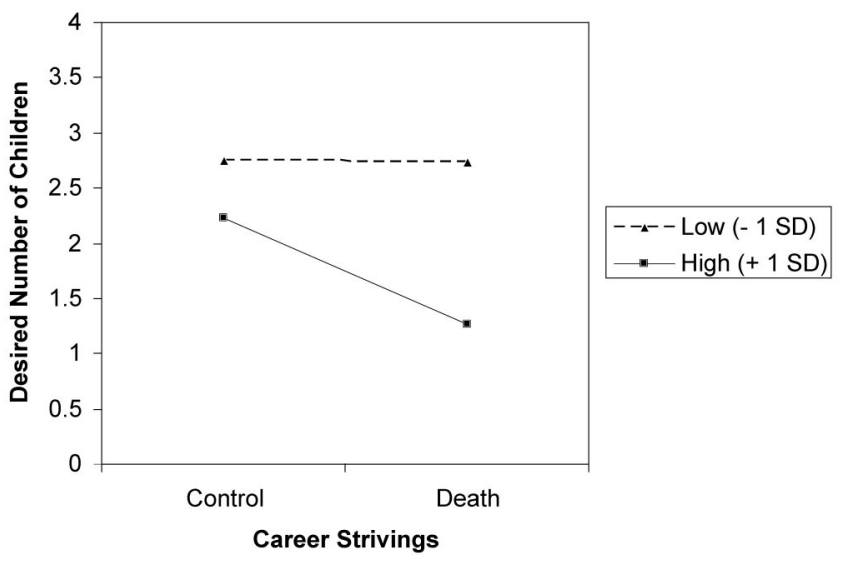

Figure 1. Procreation strivings for female participants as indicated by the number of desired children, as a function of a Mortality Salience $\times$ Career Striving (plus or minus one standard deviation) interaction (Study 3 ).

\section{Discussion}

The results of Study 3 replicate the findings of Studies 1 and 2, showing that men but not women increase their desired number of offspring as a function of mortality salience. In addition, the findings of this study provide evidence in support of our position for why this would be the case. Specifically, we argued that women having offspring comes with a potential cost to their career, whereas for men, this is not the case. In support of this argument, we found that career striving moderated the effects of mortality salience for women but not for men. In fact, when women were highly invested in their careers, mortality salience actually led to a significantly reduced desire for offspring. In addition, we replicated the finding of Study 1, revealing that such effects were independent of participants' current relationship status.

Moreover, Study 3 revealed that participants (both men and women) with a relatively strong desire for offspring expressed less interest in having sex. In line with previous terror management findings (Goldenberg et al., 1999, 2002), participants had relatively less desire to have sex after a brief contemplation of their own mortality. These findings, in conjunction with the finding that the mortality salience effect on sexual desire was not moderated by gender, render the alternative explanation that the effects of mortality salience on the desire for offspring (found only among men) could be accounted for by sexual desire extremely unlikely.

One would expect that when women are not invested in their careers at all, mortality salience should increase the desire for offspring, as it has been found for men. We did not find this to be the case at one standard deviation below the mean for career striving. However, it is important to note that in our sample of participants (i.e., students), even those who scored relatively low in career strivings were likely still committed to their careers. Moreover, as Figure 1 shows, women who scored low on career striving expressed an interest in having almost three children whether mortality was salient. This figure is comparable with the ceiling across all our studies. A desire for having three children might be the limit for most participants (indeed, only approxi- mately $6 \%$ of the female participants indicated the desire for more than three children). Thus, the absence of an increased desire for offspring at one standard deviation below the mean after mortality salience as compared with the control condition might be accounted for by a ceiling effect on number of desired children. On a theoretical level, however, our pattern of results, in which career striving is conceptualized as a continuous variable that is linearly related to mortality concerns to affect desire for offspring among women, suggests that as women get lower on the continuum of career striving, the response to mortality concerns would be to desire more offspring. This would suggest that for women the desire for offspring may still be a viable defense against mortality concerns under conditions in which it does not conflict with other meaning-proving cultural worldviews. In Study 4, we attempted to provide more direct evidence for this position by manipulating beliefs about the compatibility of a successful career and having children for women.

\section{Study 4}

Study 4 was designed to more directly test our hypothesis that concerns about the costs of motherhood on career success can inhibit women's desire for offspring in response to mortality salience. Specifically, we aimed to manipulate female participants' views with respect to the advisability of having children in conjunction with a successful career. Subsequent to a mortality salience prime and prior to the desire for offspring measure, participants read one of two bogus newspaper articles about a purported scientific study finding that having children is either incompatible or compatible with career success for women. Because the belief that children can hinder a woman's career success has been found to be the dominant view in Western societies (Proctor \& Roberts, 1987) and was also found to be the majority opinion among women (and more so than among men) in a student sample recruited from the same population as these studies, ${ }^{1}$ it was expected that the newspaper article in which careers and children are described as incompatible would only reconfirm the prevailing worldview and lead to the same pattern of results as found in Studies 1-3 among female participants. That is, we expected no increase in women's desired number of children after mortality salience compared with a neutral condition. However, if the failure to find increases in women's desired number of offspring in response to mortality salience in the previous studies could be attributed to concerns about the negative impact of children on women's careers, in undoing this belief, we hypothesized that women would respond to mortality salience with an increased desire for offspring. If we were to find that providing evidence contra-

\footnotetext{
${ }^{1}$ In an unrelated study (Wisman, 2003, 76) female participants (average age $=21$ years) indicated a dichotomous yes-no response to the following question: "Do you think that having children will affect your career chances negatively?" The majority $(66 \%)$ of these women indicated agreement with the idea that it is not advisable to combine having children and a career. In addition, in another study (Wisman, 2004) male and female participants ( 35 women and 16 men, average age $=19$ years) were asked the following questions on a 9-point scale ranging from 1 (not at all) to 9 (very much): "To what extent do you desire to have children?"; "To what extent do you think that having children will obstruct your career
} 
dicting the incompatibility of children and careers for women actually led women to respond to mortality salience as did the men in the previous studies, then this would provide important evidence in favor of our hypothesis that concerns about one's career can suppress an increased desire for offspring in response to mortality salience for women.

In addition, the current study was designed to test the hypothesis that career strivings play a central role in most female student participants' worldviews and that in the face of mortality concerns these strivings can override the desire for offspring. Therefore, participants were also provided with a measure that assessed the relative value placed on career over family. It was expected that individuals reminded of their own mortality would be relatively more likely to opt for a career over a family.

\section{Method}

\section{Participants and Design}

A total of 80 undergraduate women from the Free University Amsterdam (average age $=21$ years) were randomly assigned to two (mortality salience: death vs. control; career and children: compatible vs. incompatible) conditions. Participants received about $\$ 2.50$ for their participation.

\section{Procedure and Materials}

On arrival in the laboratory, participants were greeted by an experimenter (who was blind to the experimental conditions) and led to separate cubicles, each containing a computer. Again, materials and instructions were administered via the computer screen.

Mortality salience and self-reported affect. The first part of the study was similar to the previous studies and contained some filler personality questionnaires, followed by the mortality salience manipulation (with the neutral TV control condition) and the PANAS.

Motherhood and children (in)compatibility prime. Participants then moved on to the second part of the study. Participants were told that they were to read a newspaper article followed by some questions about their reaction to the article. Participants in the career-children compatibility condition received a purported newspaper article that stated the following:

Almost $84 \%$ of women that have children are more satisfied with their jobs and earn more than comparable childless colleagues of the same age ... "We think it a matter of priority," suggests Professor Dr. Bernard Schafely, one of the researchers of the University of Utrecht ... "the switch from raising a child to good functioning on the job floor, appears to be a smaller leap then one would expect." Anyway, it is very good news for women who have children ... There may be

chances?"; and "To what extent do you think having children obstructs career chances more for women then for men?" Regression analysis revealed that the more participants thought having a career would obstruct their career success, the less they desired offspring, $b=-.557, S E=.070$, $t(47)=-4.69, p<.0005$. Moreover, female participants $(M=5.51, S D=$ 1.06) were more convinced that having children would obstruct their career than male participants $(M=4.94, S D=0.85), F(1,49)=4.29, p<.005$, and female participants thought that having children was more negative for women than for men $(M=6.11, S D=1.34$; compared with $M=5.19$, $S D=1.60$ among male participants), $F(1,49)=4.29, p<.005$. In sum, both data support our hypothesis that the dominant view among our population (and especially among women) is that children are a hindrance to a woman's career success. also disadvantages associated having children, but overall having children is definitely compatible with achieving a career.

Participants were told the following: "This is one of the outcomes of a long-term survey among 8,000 career women. In this research the careers of women with no children were compared with the careers of women with children." Participants in the career-children incompatibility condition read the same article with the italicized words rephrased oppositely.

Desire for offspring. As in Studies 1-3, desire for offspring was assessed with the same two questions about how many children participants desired. Again, the two items were highly reliable (Cronbach's $\alpha=$ .90).

Career strivings. Participants were then provided with four items designed to assess relative value placed on one's career over having a family. To camouflage our specific interest in career versus children, we also asked participants to choose between a career or friends/fame/love For example, the item of interest read as follows: "I would choose a family life over having a career." Participants could either "agree" or "disagree" with the proposition. For our purposes then, the score on this measure was a dichotomous "agree/disagree" response to placing one's career over one's desire for having children.

Finally, participants filled out a form that contained demographic items, including relationship status. As a manipulation check, participants were asked about the purpose of the experiment and about the outcomes and content of the investigation described in the "newspaper article." Participants were then debriefed and dismissed.

\section{Results}

\section{Manipulation Checks}

The first manipulation check assessed participants' suspicion as to the purpose of the experiment. None of the participants guessed the purpose of the experiment. Second, participants were asked to describe the content of the newspaper article to confirm that they read and attended to the information presented. All participants in the career-children incompatibility article reported that the article stated that children negatively had an impact on women's careers, whereas all the participants in career-children compatibility condition answered that children were not harmful to women's careers.

\section{Self-Reported Affect}

A 2 (mortality salience: death vs. control) $\times 2$ (career and children: compatible vs. incompatible) ANOVA was conducted on the two subscales of the PANAS. As in Studies 1 and 3, these analyses did not reveal significant effects on the subscales of the PANAS (all $p$ s $>.40$ ). Therefore, the data below were not analyzed with mood as a covariate.

\section{Number of Desired Children}

Desire for offspring composite was subjected to a 2 (mortality salience: death vs. control) $\times 2$ (career and children: compatible vs. incompatible) between-subjects ANOVA. The results yielded a Mortality Salience $\times$ Essay interaction, $F(1,75)=4.81, p<.04$. Specifically, as shown in Table 5, in the children-career incompatibility condition, women's desire for children was not significantly affected by mortality salience $(p>.20)$. Note that the pattern of means in the negative children-career condition is comparable with the base rate that was found for female participants in Studies 1-3. However, in this study, when participants had 
Table 5

Procreation Strivings for Female Participants as Indicated by the Number of Desired Children, as a Function of a Mortality Salience $\times$ Worldview Manipulation (Study 4)

\begin{tabular}{ccc}
\hline & \multicolumn{2}{c}{ Career and children } \\
\cline { 2 - 3 } Mortality salience & Incompatible & Compatible \\
\hline Control & & \\
$M$ & 2.75 & 2.05 \\
$S D$ & 0.73 & 1.29 \\
$n$ & 20 & 20 \\
Death & & \\
$M$ & 2.38 & 2.75 \\
$S D$ & 0.76 & 1.43 \\
$n$ & 20 & 20 \\
\hline
\end{tabular}

been primed with a positive association between children and a career, they now expressed an increased desire for children after mortality salience, $F(1,78)=4.10, p=.046$. Thus, the information arguing in support of the compatibility of having children and a career for women led to a reaction to mortality salience that was compatible to men's responses in the previous studies.

We did also find an unexpected effect of essay within the TV control condition, in which people exposed to the career and children compatible essay expressed less of a desire for offspring than women in the incompatibility essay condition, $F(1,78)=$ $4.10, p=.046$.

\section{Career Strivings}

To examine the effects of mortality salience on the relative value placed on women's careers versus offspring, we conducted a 2 (mortality salience: death vs. control) $\times 2$ (career and children: compatible vs. incompatible) $\times 2$ (life choice: career vs. children) logistic regression analysis. This analysis revealed a significant Life Choice $\times$ Mortality Salience interaction, $\chi^{2}(1, N=76)=4.41, p<.04$. In the neutral condition, only $15 \%$ of the participants indicated choosing a career over having children in their life course, whereas in the mortality salience condition, $35 \%$ chose for a career over having children. Thus, mortality salience seemed to promote an increase in how much women valued their careers over having children. There was no effect of the essay manipulation ( $p>.10)$, and there was not any interaction between the essay manipulation and the other variables in the analyses ( $p s>.81$ ). Finally, we repeated the logistic regression analyses above with the remaining items (friends/fame/love) and found no effects ( $p$ s $>.20)$.

\section{Relationship}

All analyses were repeated with relationship as a factor. There were no effects on the relationship factor $(p s>.20)$, and including relationship as a factor did not alter the significant pattern of any results.

\section{Discussion}

In Study 4, support was provided for the hypothesis that women's procreation strivings are inhibited under mortality salience by negative worldviews about combining a career and having chil- dren. Specifically, we found that female participants who were led to believe that having children was compatible with having a successful career displayed a relatively stronger desire for offspring under mortality salience compared with the control condition. These findings support the hypothesis that female participants, just like male participants, may exhibit an increased desire for offspring after mortality salience when such desire is not inhibited by a conflicting desire to have a successful career. Consistent with the findings in Studies 1-3, female participants who were led to believe that research revealed that having offspring exerts a negative influence on career success did not desire more children after mortality salience compared with the neutral condition, but again, they showed a trend toward desiring less offspring.

The data did reveal one unexpected finding in which the career-children incompatibility essay actually increased the desire for offspring in the absence of mortality salience. Frankly, we are not sure as to why this is the case. One possibility is that the career-children incompatibility essay may have provoked psychological reactance (i.e., when one feels that one's freedom to choose has been reduced, one often views the "forced" alternative as less desirable; Brehm \& Brehm, 1981). That is, participants may have reacted against the pedagogic scientific evidence trying to persuade them against the advisability of having a career in conjunction with having children. However, when mortality salience was primed and having a career may have become increasingly important to women, the argument may have been viewed as more consistent with their own personal beliefs and, thus, less likely to inspire reactance. Of course, such post hoc theorizing is speculative, and more research would be necessary to test such ideas and determine whether such a finding is even a replicable effect. However, for the purpose of the current research, we were interested in the differential effects of mortality salience as a function of the essay prime condition and, specifically, whether mortality salience could increase desired offspring for women when concerns about the threat of children to their career had been eradicated. The results provide support for this hypothesis.

This experiment also revealed that mortality salience promoted career strivings over having a family. Of course, the findings for career striving in response to mortality salience was assessed in the context of an experiment in which participants had been exposed to one of the two essays about the compatibility or incompatibility of having a career and children. However, even controlling for exposure to this prime, mortality salience led to a heightened emphasis on career strivings over having children, thus providing additional support for our hypothesis that concerns about one's career are worldview relevant for women and can suppress an increased desire for offspring after mortality salience. Although one might have expected the essay manipulation to interact with mortality salience, the difference between this dependent measure and the desire for offspring is that expressing increased desire for offspring as a function of the essay prime was not at the cost of one's career (e.g., the essay made evident the compatibility of the two), whereas the dichotomous measure intentionally did not allow for the having both-career and children. 


\section{General Discussion}

In the current research, we examined the role of mortality salience and gender on the desire for offspring. On the basis of TMT, we hypothesized that reminders of mortality should promote a desire for offspring. However, we also hypothesized that this effect should occur to the extent that it does not conflict with other self-relevant worldviews that also serve to manage existential concerns. Therefore, we specifically expected that mortality salience would increase the desire for offspring for men only, because for women children can represent a threat to another culturally valued domain that can shield against existential concerns (i.e., career success).

In support of these hypotheses, three experiments (Studies 1-3) unveiled a Gender $\times$ Mortality Salience interaction on a desire for offspring with mortality salience leading male participants, but not female participants, to express increased procreation striving as indicated by the number of desired children. Thus, on the surface it appears as if the desire for offspring is not part of women's defense system against mortality concerns. However, support was found for the hypothesis that women's desire for offspring may have been inhibited by a conflicting desire to have a successful career (which can also be sought as a defense against mortality salience, as demonstrated in Study 4). First, two pilot studies (see Footnote 1) revealed that the governing view among our population (and especially among female students) is that children are a potential impedance to a woman's career prosperity. Then, we demonstrated direct support for our hypothesis by the finding that, exclusively among women, career strivings moderated the effects of mortality salience on a desire for offspring (Study 3). Female participants who were highly invested in their careers showed a significantly decreased desire for offspring after mortality salience. Finally, in a fourth experiment, we directly tested the hypothesis that women's desire for offspring is inhibited by negative worldviews with regard to the impact of children on one's career. Study 4 revealed that when women were exposed to an essay emphasizing the compatibility of offspring and career success, they displayed an increased desire for offspring as a function of mortality salience. These findings support the hypothesis that female participants, just like male participants, may desire offspring in response to mortality concerns when such desire is not inhibited by a conflicting desire to have a successful career. Thus, overall the findings support the proposition that a desire for offspring can function as a terror management defense mechanism.

\section{The Why, When, and for Whom of the Desire for Offspring}

Although we have suggested that the desire for offspring can serve as a terror management defense, we have been fairly broad in our conceptualization for why. This is not because we are unclear as to which mechanism is being served-meaning, selfesteem, immortality striving-but rather because we assume that each of these mechanisms work in tandem when it comes to the desire for offspring. According to TMT, people can obtain a sense of immortality by feeling that they are living up to the standards (i.e., obtaining self-esteem) of one's meaning providing worldview. The desire for offspring is assumed to operate on all these levels, offering a comprehensive symbolic defense mechanism. In much the same way that preparing a child for his first bar mitzvah can give parents a feeling of pride (self-esteem) - because it is experienced as a meaningful act that provides a sense of immortality by continuing a tradition that has existed for ages-desiring offspring can represent a multiple powerful pathway to people's symbolic anxiety buffer and, as such, serve as a vital terror management mechanism within the context of an individual's worldview.

Moreover, on the basis of TMT, we made specific causal predictions as for whom and under what conditions people make use of the desire for offspring as a defense against existential concerns. In accordance with Tesser et al.'s (2000) work on the plasticity of self-defense, recent research suggests that the defense implemented to protect one's self against existential terror depends to a great extent on what aspect of the self or one's worldview is currently most salient, accessible, or psychologically pressing (see, e.g., Dechesne et al., 2003; Hart et al., in press; McGregor et al., 1998; Wisman \& Koole, 2003). With respect to the current studies, male participants defended against existential concerns with a desire for offspring, presumably because children provide a pathway to a meaningful, valuable, and immortal existence. However, for the women in our studies (i.e., students), the desire for offspring is unlikely to function as an unambiguous anxiety buffer because children represent a threat to alternative means of managing existential terror. It is not surprising, therefore, that women did not routinely defend in this manner. Indeed, Study 2 revealed that female participants displayed worldview defense after mortality salience without showing an increased desire for offspring. In Study 4, providing more direct evidence for the plasticity of defense, female participants defended with a desire for offspring if they were led to believe that a desire for offspring was compatible with career strivings. So the desire for offspring was enhanced as a function of mortality salience only to the extent that it did not interfere with other meaningful aspects of one's worldview. Thus, these findings offer support for the hypothesis that people can make use of the shielding capacities of defense against existential anxiety in a most flexible manner.

An interesting finding was that male participants showed no worldview defense after expressing an increased desire for offspring as a function of mortality salience (Study 2). This finding suggests that a desire for offspring was substituted in the place of a more traditional worldview defense. A desire for offspring might be distinctively suitable to substitute for other defensive strategies because it offers a comprehensive pathway to self-esteem, meaning, and a sense of immortality. In addition, in contrast to other defenses that can often be destructive, such as aggression toward people who do not share one's worldviews (McGregor et al., 1998), a desire for offspring represents a more positive (i.e., procreative) means of protecting oneself against existential terror.

\section{Alternative Perspectives and Future Research}

There are, however, some alternative perspectives that may also account for procreation strivings. It seems plausible, for instance, that a desire for offspring originates in procreation strivings that people share with all living species. However, as has been briefly argued in the introduction, although intuitively appealing, the idea that a desire for offspring is an evolved instinctive drive (Deutsch, 1945; Kephart, 1966) has not been supported (Veenhoven, 1975). 
There is no evidence that people are equipped with a unique module for a desire for offspring, and several arguments have been brought forward against this idea (Veenhoven, 1975). For instance, Veenhoven (1975) pointed out that animals are not motivated by long-term effects, such as having offspring. Moreover, reproductive behavior is usually governed by more simple mechanisms such as a desire for sex (for a more extended overview and further arguments, see Veenhoven, 1975).

Although the conscious desire for offspring might not be directly evolved, one can argue that such a conscious desire may be attached to hard-wired innate modules. For instance, we can speculate that people's conscious desire for offspring is entangled with an innate sex drive, and as such, people's desire for sex could operate as a catalyst for desiring offspring. Moreover, if we assume that this potential association between sex and a desire for offspring is even enhanced after reminders of mortality, then this may pose an alternative account for the current findings. However, this hypothesis failed to garner empirical support in the current research. Indeed, we found the opposite pattern; participants' desire for offspring was negatively correlated with their sexual appetite (Study 3). Moreover, in this research, mortality salience decreased participants desire to have sex, and previous research has revealed that sexuality can be experienced as relatively more threatening after a confrontation with mortality (Goldenberg et al., 1999, 2002). Furthermore, as has been mentioned previously, it is clear that people can desire to have children independent of a desire for sex. Thus, we believe that it is unlikely that the desire for offspring as a defense against existential concerns is attributable to sexual desire. If sexuality plays any significant role in participant's desire for offspring at all, then we suspect it is intertwined with more symbolic structures, such as love and close relationships (Goldenberg et al., 2002; Mikulincer et al., 2003).

Thus, another alternative explanation might be that people's desire for offspring is a by-product of people's desire to form close relationships. Indeed, it has been found that mortality salience motivates people to seek and maintain close relationships (Mikulincer et al., 2003). Consequently, one could argue that the increased desire for offspring after mortality salience is confounded by people's relationship strivings. If this relationship exists, then indeed we might expect that having a stable relationship would interact with participants' desire for offspring. In the current research, however, it was found that there was no relation between participants' relationship status and participants' desire for offspring after mortality salience. Moreover, if a desire for offspring is merely a by-product of close-relationship strivings, then we might expect-in light of the Gender $\times$ Mortality Salience interaction in the current research-that women have a relatively weaker desire for close relationships after reminders of mortality. This is unlikely, however, because recent research has revealed that romantic accessibility is more likely for women than for men when facing existential concerns (Arndt, Greenberg, \& Cook, 2002). Certainly, the current finding that a desire for offspring can function as an individual symbolic solution to deal with existential concerns does not rule out the possibility that a desire for offspring can be simultaneously related to both relationship strivings and an individual desire to cope with existential concerns. A study specifically focused on relationships and the desire for offspring could offer additional insights in the quest for understanding people's motivation to desire children. Transposing the intraindividual con- text to an interindividual context may offer an important and promising pathway to extend the current issues.

Although the current research shows that reminders of mortality can increase a desire for having children when to do so does not conflict with other defensive needs, we have not yet considered the role of actually having children in coping with existential concerns. As we already suggested, children may function as an extension of the symbolic self (Sedikides \& Skowronski, 1997), and as such, children in actuality (as opposed to the "idea" of children) might help to ward off existential concerns. People might for instance feel that death is less threatening because they know that they will continue to exist in a literal and symbolic sense. Or in a related vein, parents might even value cultural normative behavior of their children more if they are reminded of their own mortality, because that kind of behavior would validate their symbolic defense system (e.g., Pyszczynski et al., 2003). Moreover, parents might bask in the glory of their successful offspring as a source of self-esteem (e.g., Cialdini et al., 1976) and it might be possible to discriminate between the death denying function of successful children versus unsuccessful children. This kind of research potentially elucidates why parents are so invested in the success of their children. Examining the death-denying functions of having children, in addition to procreation strivings, constitutes an important issue for future research.

\section{Concluding Remarks}

Although researchers have extensively studied procreation behavior among animals ranging from the white whale to the Amazon ant (Dekkers, 2002), human procreation in its full complexity has received relatively scant attention. In the current research, we have shown that reminders of mortality can promote people's desire for offspring; but procreation strivings, as understood as functioning as a psychological defense, can also be inhibited by other needs also functioning to buffer mortality concerns. In this way, we have demonstrated that the desire for offspring can be understood as among the myriad of defenses that one may use in the service of managing existential concerns. However, the desire for offspring is not merely another defense, but rather the desire for offspring constitutes one of the most important of all human motivations; for our species continuation is dependent on it. We view the finding that the desire for offspring can assuage human concerns about mortality as encouraging, because it suggests that as a reaction to mortality concerns-induced perhaps by a terrorist attack-people may desire to create new life instead of wars.

\section{References}

Arndt, J., Greenberg, J., \& Cook, A. (2002). Mortality salience and the spreading activation of worldview-relevant constructs: Exploring the cognitive architecture of terror management. Journal of Experimental Psychology, 131, 307-324.

Arndt, J., Greenberg, J., Pyszczynski, T., \& Solomon, S. (1997). Subliminal exposure to death-related stimuli increases defense of the cultural worldview. Psychological Science, 8, 379-385.

Arndt, J., Greenberg, J., Schimel, J., Pyszczynski, T., \& Solomon, S. (2002). To belong or not to belong, that is the question: Terror management and identification with gender and ethnicity. Journal of Personality and Social Psychology, 83, 26-43.

Arndt, J., Greenberg, J., Solomon, S., Pyszczynski, T., \& Simon (1997). 
Suppression, accessibility of death-related thoughts, and cultural worldview defense: Exploring the psychodynamics of terror management. Journal of Personality and Social Psychology, 73, 5-18.

Baron, R. M., \& Kenny, D. A. (1986). The moderator-mediator variable distinction in social psychological research: Conceptual, strategic, and statistical considerations. Journal of Personality and Social Psychology, 51, 1173-1182.

Baumeister, R. F. (1991). The meanings of life. New York: Guilford Press. Becker, E. (1973). The denial of death. New York: Free Press.

Belsky, J., Steinberg, L., \& Draper, P. (1991). Childhood experience, interpersonal development, and reproductive strategy. Child Development, 62, 647-670.

Ben-Ari, O. T., Florian, V., \& Mikulincer, M. (1999). The impact of mortality salience on reckless driving: A test of terror management mechanisms. Journal of Personality and Social Psychology, 76, 35-45.

Biernat, M., \& Wortman, C. B. (1991). Sharing of home responsibilities between professionally employed women and their husbands. Journal of Personality and Social Psychology, 60, 844-860.

Brehm, S. S., \& Brehm, J. W. (1981). Psychological reactance: A theory of freedom and control. New York: Academic Press.

Buss, D. M. (1996). The evolutionary psychology of human social strategies. In E. Higgins \& A. Kruglanski (Eds.), Social psychology: Handbook of basic principles (pp. 3-38). New York: Guilford Press.

Buss, D., \& Kenrick, D. T. (1998). Evolutionary social psychology. In D. T. Gilbert, S. T. Fiske, \& G. Lindzey (Eds.), The handbook of social psychology (Vol. 2, 4th ed., pp. 915-981). Boston: McGraw-Hill.

Byrne, D. (1971). The attraction paradigm. New York: Academic Press.

Callan, V. J. (1987). The personal and marital adjustment of mothers and of voluntarily and involuntarily childless wives. Journal of Marriage and the Family, 49, 847-856.

Callan, V. J., \& Hennessey, J. F. (1989a). Psychological adjustment to infertility: A unique comparison of two groups of infertile women, mothers and women childless by choice. Journal of Reproductive \& Infant Psychology, 7, 105-112.

Callan, V. J., \& Hennessey, J. F. (1989b). Strategies for coping with infertility. British Journal of Medical Psychology, 62, 343-354.

Cassidy, M. L., \& Warren, B. O. (1996). Family employment status and gender role attitudes: A comparison of women and men college graduates. Gender and Society, 10, 312-329.

Cialdini, R. B., Borden, R. J., Thorne, A., Walker, R. M., Freeman, S., \& Sloan, L. R. (1976). Basking in reflected glory: Three (football) field studies. Journal of Personality and Social Psychology, 34, 366-375.

Cohan, C. L., \& Cole, S. W. (2002). Life course transitions and natural disaster: Marriage, birth, and divorce following Hurricane Hugo. Journal of Family Psychology, 16, 14-25.

Cohen, J., \& Cohen, P. (1983). Applied multiple regression/correlation analysis for the behavioral sciences (2nd ed.). Hillsdale, NJ: Erlbaum.

Daly, M., \& Wilson, M. (1988, October 28). Evolutionary social psychology and family homicide. Science, 242, 519-524.

Dawkins, R. (1982). The extended phenotype. Oxford, England: Oxford University Press.

Dechesne, M., Greenberg, J., Arndt, J., \& Schimel, J. (2000). Terror management and sports fan affiliation: The effects of mortality salience on fan identification and optimism. European Journal of Social Psychology, 30, 813-835.

Dechesne, M., Janssen, J., \& van Knippenberg, A. (2000). Derogation and distancing as terror management strategies: The moderating role of need for closure and permeability of group boundaries. Journal of Personality and Social Psychology, 79, 923-932.

Dechesne, M., Pyszczynski, T., Arndt, J., Ransom, S., Sheldon, K. M., van Knippenberg, A., \& Janssen, J. (2003). Literal and symbolic immortality: The effect of evidence of literal immortality on self-esteem striving in response to mortality salience. Journal of Personality and Social Psychology, 84, 722-737.
Dekkers, M. (2002). De Larf [The larva: On children and metamorphosis]. Amsterdam, the Netherlands: Uitgeverij Contact.

Deutsch, H. (1945). The psychology of women: Motherhood (Vol. 2). New York: Grune \& Stratton.

Florian, V., \& Mikulincer, M. (1997). Fear of death and the judgment of social transgressions: A multidimensional test of terror management theory. Journal of Personality and Social Psychology, 73, 369-380.

Florian, V., \& Mikulincer, M. (1998a). Symbolic immortality and the management of the terror of death: The moderating role of attachment style. Journal of Personality and Social Psychology, 74, 725-734.

Florian, V., \& Mikulincer, M. (1998b). Terror management in childhood: Does death conceptualization moderate the effects of mortality salience on acceptance of similar and different others? Personality and Social Psychology Bulletin, 24, 1104-1112.

Goldenberg, J. L., Arndt, J., Hart, J., \& Brown, M. (in press). Dying to be thin: The effects of mortality salience and body-mass index on restricted eating among women. Personality of Social Psychology Bulletin.

Goldenberg, J. L., Cox, C. R., Pyszczynski, T., Greenberg, J., \& Solomon, S. (2002). Understanding human ambivalence about sex: The effects of stripping sex of meaning. Journal of Sex Research, 39, 310-320.

Goldenberg, J. L., Pyszczynski, T., McCoy, S. K., Greenberg, J., \& Solomon, S. (1999). Death, sex, love, and neuroticism: Why is sex such a problem? Journal of Personality and Social Psychology, 77, 11731187.

Greenberg, J., Pyszczynski, T., Solomon, S., Rosenblatt, A., Veeder, M., Kirkland, S., \& Lyon, D. (1990). Evidence for terror management theory: II. The effects of mortality salience on reactions to those who threaten or bolster the cultural worldview. Journal of Personality and Social Psychology, 58, 308-318.

Greenberg, J., Pyszczynski, T., Solomon, S., Simon, L., \& Breus, M. (1994). Role of consciousness and accessibility of death-related thoughts in mortality salience effects. Journal of Personality and Social Psychology, 67, 627-637.

Greenberg, J., Simon, L., Pyszczynski, T., Solomon, S., \& Chatel, D. (1992). Terror management and tolerance: Does mortality salience always intensify negative reactions to others who threaten one's world view? Journal of Personality and Social Psychology, 63, 212-220.

Greenberg, J., Solomon, S., \& Pyszczynski, T. (1997). Terror management theory of self-esteem and cultural worldviews: Empirical assessments and conceptual refinements. Advances in Experimental Social Psychology, 29, 61-139.

Greil, A. L. (1997). Infertility and psychological distress: A critical review of the literature. Social Science and Medicine, 45, 1679-1704.

Hamilton, W. D. (1964). The genetical theory of social behavior: I and II. Journal of Theoretical Biology, 7, 1-52.

Hamon, R. R., \& Blieszner, R. (1990). Filial responsibility expectations among adult child-older parent pairs. Journal of Gerontology, 45, $110-112$.

Hart, J., Shaver, P. R., \& Goldenberg, J. L. (in press). Attachment, self-esteem, worldviews, and terror management: Evidence for a tripartite security system. Journal of Personality and Social Psychology.

Ingraham, C. (1999). White weddings: Romancing heterosexuality in popular culture. New York: Routledge.

Kephart, W. (1966). The family, society, and the individual. New York: Houghton Mifflin.

Kiecolt, K. J. (2003). Satisfaction with work and family life: No evidence of a cultural reversal. Journal of Marriage and the Family, 65, 23-25.

Lifton, R. J. (1979). The broken connection: On death and the continuity of life. American Psychiatric Publishing.

Littlefield, C. H., \& Rushton, J. P. (1986). When a child dies: The sociobiology of bereavement. Journal of Social Psychology, 51, 797802.

Long, M. V., \& Martin, P. (2000). Personality, relationship closeness, and 
loneliness of the oldest old and their children. Journals of Gerontology: Psychological Sciences, 55, 311-319.

MacKinnon, D. P., Lockwood, C. M., Hoffman, J. M., West, S. G., \& Sheets, V. (2002). A comparison of methods to test the significance of the mediated effect. Psychological Methods, 7, 83-104.

Martin, L. L. (1999). I-D compensation theory: Some implications of trying to satisfy immediate-return needs in a delayed-return culture. Psychological Inquiry, 10, 195-208.

Mason, K. O., \& Lu, Y. (1988). Attitudes toward women's familial roles: Changes in the United States, 1977-1985. Gender and Society, 2, $39-57$.

McGregor, H., Lieberman, J. D., Greenberg, J., Solomon, S., Arndt, J., Simon, L., \& Pyszczynski, T. (1998). Terror management and aggression: Evidence that mortality salience motivates aggression against worldview-threatening others. Journal of Personality and Social Psychology, 74, 590-605.

McKinney, K. (1987). Age and gender differences in college students' attitudes toward women: A replication and extension. Sex Roles, 17, 353-358.

Mikulincer, M., Florian, V., \& Hirschberger, G. (2003). The existential function of close relationships: Introducing death into the science of love. Personality and Social Psychology Review, 7, 20-40.

Norenzayan, A., Hansen, I. G., \& Atran, S. (2003). Belief in supernatural agents in the face of death. Manuscript submitted for publication.

Ochsmann, R. (1984). Belief in afterlife as a moderator of fear of death? European Journal of Social Psychology, 14, 53-67.

Ochsmann, R., \& Mathay, M. (1996). Depreciating of and distancing from foreigners: Effects of mortality salience. Unpublished manuscript, Universitat Mainz, Germany.

Osarchuk, M., \& Tatz, S. J. (1973). Effect of induced fear of death on belief in afterlife. Journal of Personality and Social Psychology, 27, 256-260.

Proctor, S., \& Roberts, S. H. (1987). Hard times-hard choices: Positive decision-making for part-time women doctors. Medical Education, 21, 260-264.

Pyszczynski, T., Greenberg, J., \& Solomon, S. (1999). A dual-process model of defense against conscious and unconscious death-related thoughts: An extension of terror management theory. Psychological Review, 106, 835-845.

Pyszczynski, T., Solomon, S., \& Greenberg, J. (2003). In the wake of 9/11: The psychology of terror. Washington, DC: American Psychological Association.

Rosenblatt, A., Greenberg, J., Solomon, S., Pyszczynski, T., \& Lyon, D. (1989). Evidence for terror management theory: I. The effect of mortality salience on reactions to those who violate or uphold cultural values. Journal of Personality and Social Psychology, 57, 681-690.

Schama, S. (1997). The embarrassment of riches: An interpretation of Dutch culture in Golden Age. New York: Vintage Books.
Sedikides, C., \& Skowronski, J. J. (1997). The symbolic self in evolutionary context. Personality and Social Psychology Review, 1, 80-102.

Solomon, S., Greenberg, J., \& Pyszczynski, T. (1991). A terror management theory of social behavior: The psychological functions of selfesteem and cultural worldviews. Advances in Experimental Social Psychology, 24, 93-159.

Spitze, G. (1988). Women's employment and family relations: A review. Journal of Marriage and the Family, 50, 595-618.

Steele, C. M. (1988). The psychology of self-affirmation: Sustaining the integrity of the self. San Diego, CA: Academic Press.

Tesser, A. (1988). Toward a self-evaluation maintenance model of social behavior. Advances in Experimental Social Psychology, 21, 181-227.

Tesser, A., Crepaz, N., Beach, S. R. H., Cornell, D., \& Collins, J. C. (2000). Confluence of self-esteem regulation mechanisms: On integrating the self-zoo. Personality and Social Psychology Bulletin, 26, 14761489.

Tesser, A., Martin, L. L., \& Cornell, D. (1996). On the substitubility of self-protective mechanisms. New York: Guilford Press.

Thornton, A. (1989). Changing attitudes toward family issues in the United States. Journal of Marriage and the Family, 5, 873-893.

Trivers, R. (1985). Social evolution. Menlo Park, CA: Benjamin Cummings.

Veenhoven, R. (1975). Is there an innate need for children? European Journal of Social Psychology, 1, 495-501.

Watson, D., Clark, L. A., \& Tellegen, A. (1988). Development and validation of brief measures of positive and negative affect: The PANAS scales. Journal of Personality and Social Psychology, 54, 1063-1070.

Wilkie, J. R. (1993). Changes in U.S. men's attitudes toward the family provider role, 1972-1989. Gender and Society, 7, 261-279.

Wilson, E. O. (1975). Sociobiology: The new synthesis. Cambridge, MA: Belknap Press.

Wisman, A. (2003). [Unpublished data]. Free University, Amsterdam, the Netherlands.

Wisman, A. (2004). The fertilizing threat of death. Manuscript in preparation.

Wisman, A., \& Koole, S. L. (2003). Hiding in the crowd: Can mortality salience promote affiliation with others who oppose one's worldviews? Journal of Personality and Social Psychology, 84, 511-526.

Wortman, C. B., Biernat, M., \& Lang, E. (1991). Coping with role overload. New York: Plenum Press.

Zhan, H. J., \& Montgomery, R. J. V. (2003). Gender and elder care in China: The influence of filial piety and structural constraints. Gender and Society, 17, 209-229.

Received December 12, 2003

Revision received November 15, 2004

Accepted March 17, 2005 